\title{
Laser Shock Peening Application as Alternative Method to Determine the Mechanical Properties of Aluminum
}

\author{
Nargis Zamil Abdulzahra ${ }^{1} \&$ Saad Naji Abood ${ }^{1}$ \\ ${ }^{1}$ Al- Nahrain University, College of Sciences, Physics Department, Baghdad, Iraq \\ Correspondence: Nargis Zamil Abdulzahra, Al- Nahrain University, College of Sciences, Physics Department, \\ Baghdad, Iraq. E-mail: ner_ner2@yahoo.com, saadnaji_95@yahoo.com
}

Received: February 4, 2018

doi:10.5539/mas.v12n12p102
Accepted: February 22, $2018 \quad$ Online Published: November 19, 2018

URL: https://doi.org/10.5539/mas.v12n12p102

\begin{abstract}
The structural, physical, and mechanical properties of laser-induced shock peening (LSP) of Aluminum before and after depositing films of different metals $(\mathrm{Cu}, \mathrm{In}$, and $\mathrm{Al})$ were investigated. The deposition of single and double films was conducted, and the physical property (density), shockwave properties (shock pressure, particle velocity, and shock velocity), mechanical properties (stress, strain, Young's s modulus, and Hardness) were calculated, Young's s modulus measured of aluminum was measured by classical method (Tensile test ) and by LSP technique, and it was found that the measured using LSP is closer to the standard value than classical method .Single film $\mathrm{Cu}$ and sandwich $\mathrm{Al} / \mathrm{Cu}$ deposited on $\mathrm{Al}$ substrate showed an enhancement in the mechanical properties rather than other films, while the deposited films of ( $\mathrm{In}, \mathrm{In} / \mathrm{Cu}$, and $\mathrm{Al} / \mathrm{In}$ ) on $\mathrm{Al}$ substrate revealed more strain and higher ductility than others.
\end{abstract}

Keywords: LSP technique, shock pressure, Thin film deposed on Al, tensile test, hardness

\section{Introduction}

Aluminum is one of the common elements that attract scientists because of the lightweight to strength, on the other hand, the hardness and wear resistance are low which limited its use in applications (Popoola et al. ,2016). When a laser pulse of high energy interacts with the material, the hot plasma is produced which is expanding at very high speed in the opposite direction of the laser. Externally expanded plasma utilizes high pressure in the direction of the interior, to form a wave of severe shock towards the interior (Pant et al., 2002).

The laser-induced shock wave has a great importance in viruses, industrial and medical applications. The distribution of the shock wave pressure is often viewed as spherically symmetric (spherical shock) (Sankin et al.2008). R. Fabbro et al. (Fabbro\& Virmont,1990) studied a practical and theoretical measurement of the plasmagenerated by the laser and confined by a cover or a layer.They developed an equation between pressure and laser intensity, which is supported by many sources of research and papers (Fabbro \& Virmont, 1990; Peyre Fabbro, 1995; Abdullahi \& Mamoun, 2014).

Sankin et al. measured pressure peaks for a shock at various positions and determined that the peak pressure at a point in the direction perpendicular to the laser beam is more than twice as high as that in the direction of the laser(Sankin et al., 2008).

The aim of this is to research investigating the experimental measurement of aluminum properties by laser-induced shock peening wave technique before and after the deposition of different metal films. The measuring and calculating include; shock wave pressure, shock wave velocity, particle velocity, stress, strain, density, Young's modulus, and hardness after the deposition of a single and double layer of metal films to find the best material that gives the aluminum substrate the optimum mechanical properties.

\section{Method}

The established work consists of the following steps:

\subsection{Laser Nd: YAG Source Setup}

A straightforward setup was adopted in this study. The setup consists of Nd: YAG laser source, high quality, $10 \mathrm{~cm}$ focal length lens, and samples; cut with relevant dimensions to fit the experiment requirement. The laser source was vertically mounted in a holder above the sample, aligned and focused by distance $9 \mathrm{~cm}$, to avoid the sputtering 
large area of the thick film because of produced great shock pressure. Figure (1) shows the setup used in the experiments.

\subsection{Metal Films Preparation}

The thick film of different materials was deposited on an Al substrate using thermal evaporation technique at the University of Al-Technology. Thick $\mathrm{Cu}, \mathrm{Al}$, and Indium (In) films were deposited on the aluminum substrate using single and two layers of different materials and measure the laser spot area before and after laser metal interaction, figure (2) shows the schematic diagram of the deposition process.

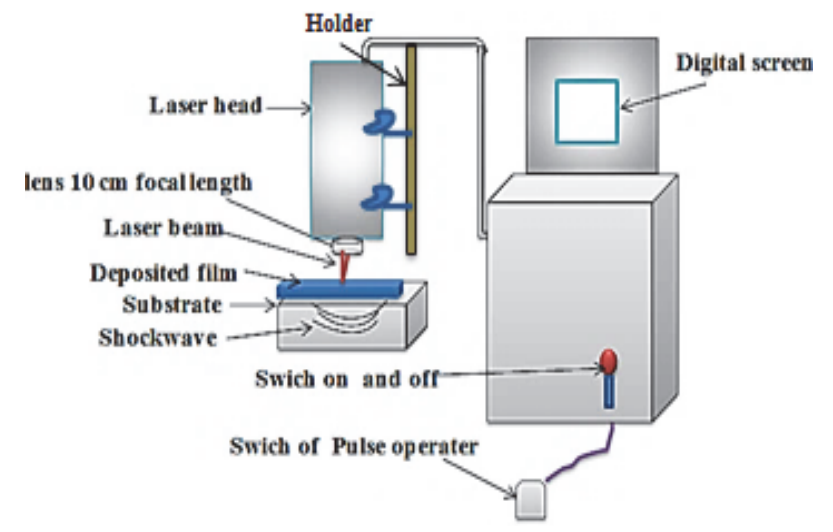

Figure 1. Experimental setup of LSP equipment

Second deposited layer

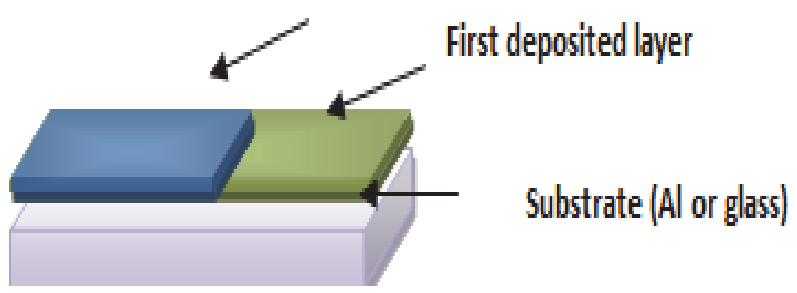

Figure 2. Schematic diagram of the thick film layers

\subsection{Metal Thickness Measurement}

All metal films that deposited were measured by an optical microscopy type (OLUMPUS BH2) connected with a digital camera and a computer, the used optical microscopy gives details in micron, that is enough for all micro structure studies. The average film thickness was: $\mathrm{Cu}(12 \mu \mathrm{m}), \mathrm{Al}(18 \mu \mathrm{m})$, In $(27 \mu \mathrm{m})$.

\subsection{Study of Shock Wave Region Effect}

The shock wave effect on the metal region was studied using a CCD camera connected with an optical system with magnification reached at 2000 times.

\subsection{The Tensile Test}

This test was accomplished after cutting the samples according to American Society for Testing and Materials (ASTM) E8/E8M-13 a standard as shown in figure (3), the specimen 5 was used in this test.

(a)

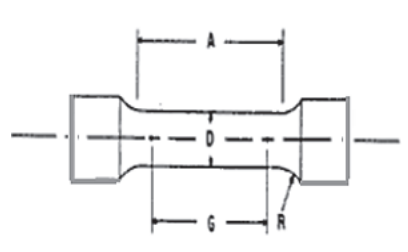

(b)

\begin{tabular}{lccccc}
\hline \multicolumn{5}{c}{$\begin{array}{c}\text { Dimensions, mm [in] } \\
\text { For Test Specimens with Gauge Length Four times the Diameter [E8] }\end{array}$} \\
\hline & Standard & \multicolumn{4}{c}{ Small-Size Specimens Proportilonal to Slandard } \\
& Specimen & & & & \\
\cline { 2 - 6 } & Specimen 1 & Specimen 2 & Specimen 3 & Specimen 4 & Specimen 5 \\
\hline G-Gauge length & $50.0 \pm 0.1$ & $36.0 \pm 0.1$ & $24.0 \pm 0.1$ & $16.0 \pm 0.1$ & $10.0 \pm 0.1$ \\
& {$[2.000 \pm 0.005]$} & {$[1.400 \pm 0.005]$} & {$[1.000 \pm 0.005]$} & {$[0.640 \pm 0.005]$} & {$[0.450 \pm 0.005]$} \\
D-Diameter (Note 1) & $12.5 \pm 0.2$ & $9.0 \pm 0.1$ & $6.0 \pm 0.1$ & $4.0 \pm 0.1$ & $2.5 \pm 0.1$ \\
& {$[0.500 \pm 0.010]$} & {$[0.350 \pm 0.007]$} & {$[0.250 \pm 0.005]$} & {$[0.160 \pm 0.003]$} & {$[0.113 \pm 0.002]$} \\
R-Radius of fillet, min & $10[0.375]$ & $8[0.25]$ & $6[0.188]$ & $4[0.156]$ & $2[0.094]$ \\
A-Length of reduced section, min (Note 2) & $56[2.25]$ & $45[1.75]$ & $30[1.25]$ & $20[0.75]$ & $16[0.625]$ \\
\hline
\end{tabular}

Figure 3 (a). Tensile sample shape, (b) dimension of Tensile sample 


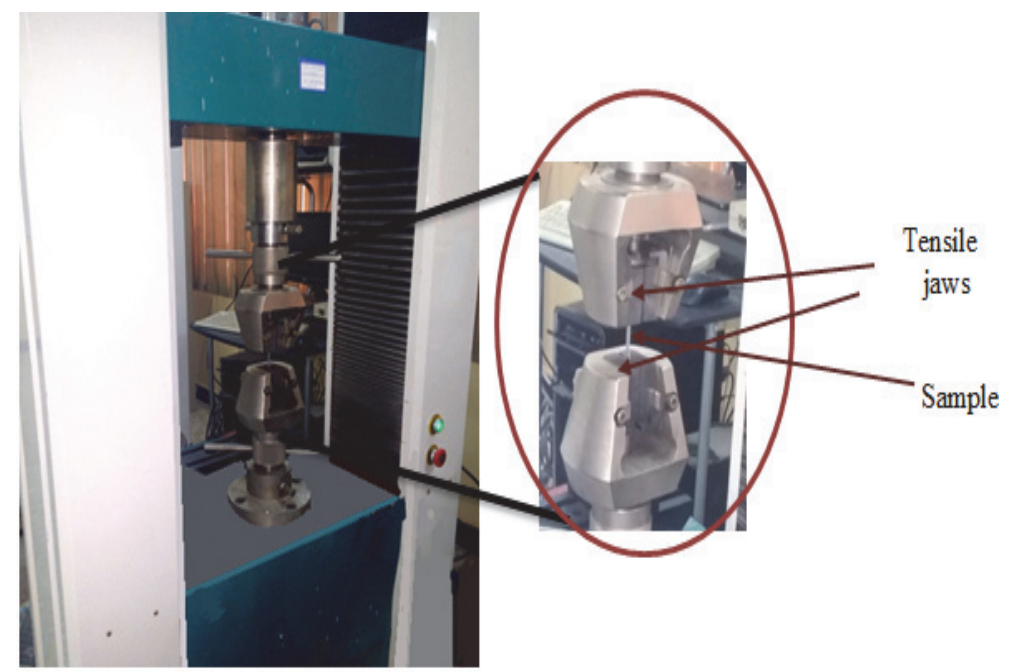

Figure 4. The tensile device setup with Aluminum sample

\section{Results}

\subsection{Morphological and Physical Properties of Al after Laser-Induced Shock Wave}

According to Maxwell's theory of electromagnetism, the energy flux (intensity) is expressed by the pointing vector $\mathrm{S}=\mathrm{E} \times \mathrm{H}$, the time average intensity $<\mathrm{S}>$ is divided by the light speed utilized by an electromagnetic wave on the target surface if the wave is absorbed completely, and the optical pressure is measured from relation (Heald\& Marion, 2012):

$$
\mathrm{P}=\frac{\langle\mathrm{s}\rangle}{\mathrm{c}}=\frac{\mathrm{I}}{\mathrm{c}}
$$

The pressure is defined as the amount of force performing per unit area (Bartelt, 2011).

$$
\mathrm{P}=\frac{\mathrm{F}}{\mathrm{A}}
$$

By equaling eq. 1 and 2, one obtains

$$
\mathrm{F}=\frac{\text { I. A }}{\mathrm{c}}
$$

Where, F: is laser force, I: Laser intensity, and c: speed of light. Table (1) shows the force of laser, intensity and energy values, the laser gives pulses by changing the applied voltage. The calibration and converting from voltage to joule is achieved by using Joule meter Genetic type .The laser intensity (I) as calculated in Eq. (2) is obtained in terms of $\mathrm{GW} / \mathrm{cm}^{2}$, either directly from the laser energy or calculated in power increments. The intensity of the laser is calculated as follows (Abdullahi \& Mamoun, 2014):

$$
\begin{array}{r}
I=\frac{P_{\text {peak }}}{A}=\frac{E}{A \cdot t_{p}}=\frac{P_{A V G}}{\text { A.f. } t_{p}} \\
\text { Fluence }=\frac{J}{\mathrm{~cm}^{2}}=\frac{E}{A}
\end{array}
$$

Where; $\mathrm{P}_{\text {peak }}$ is peak power $(\mathrm{W}), \mathrm{E}$ laser energy $(\mathrm{J}), \mathrm{P}_{\mathrm{AVG}}$ average power in $(\mathrm{W}), \mathrm{f}$ laser frequency in $(\mathrm{HZ}), \mathrm{t}_{\mathrm{p}}$ Pulse time in nanoseconds, A laser spot area is in $\mathrm{cm}^{2}$ the spot area is measured using carbon black paper because its absorption is high and has low thermal diffusivity rather than other materials.

\subsection{Shock Wave Parameter and Properties}

The pressure due to shock wave effect could be measured when the size of the Gaussian laser beam is relatively great. The shock model makes modifications to Fabbro's model after assuming that the laser beam spot size is in the order of microns. The 1-D assumption is followed, but the 2-D equivalence is considered to account for the small laser spot size (Abdullahi \& Mamoun, 2014). 
Table 1. Laser energy parameters, the spot area using carbon paper was $1.94 \times 10^{-5} \mathrm{~m}^{2}$

\begin{tabular}{|c|c|c|c|}
\hline Laser voltage $(\mathrm{V})$ & Laser energy $(\mathrm{mJ})$ & Laser intensity $\left(\mathrm{W} / \mathrm{m}^{2}\right) \times 10^{10}$ & Laser force $(\mathrm{mN})$ \\
\hline 500 & 5 & 3.69 & 2.38 \\
\hline 510 & 10 & 7.38 & 4.76 \\
\hline 520 & 20 & 14.8 & 9.52 \\
\hline 530 & 30 & 22.1 & 14.29 \\
\hline 540 & 40 & 29.5 & 19.05 \\
\hline 550 & 50 & 36.9 & 23.81 \\
\hline 560 & 60 & 44.3 & 28.57 \\
\hline 570 & 70 & 51.7 & 33.33 \\
\hline
\end{tabular}

Where, P: shock pressure, $\mathrm{Z}$ : acoustic impedance of material, $\rho$ : density $\mathrm{V}_{1}$ : velocity of acoustic waves in the material (shock wave velocity). When using a confining medium, the acoustic impedance $\left(z=\frac{2}{\left(\frac{1}{z 1}+\frac{1}{z 2}\right)}\right)$ Is expressed in terms of those of the confining medium $\left(\mathrm{z}_{1}\right)$ and the target material $\left(\mathrm{z}_{2}\right)$. Table (1) shows the used material properties. The particle velocity related to shock pressure and acoustic impedance (z), given as (Marsh,1980):

$$
\mathrm{V}_{\mathrm{p}}=\frac{\mathrm{P}}{\mathrm{z}}
$$

The Shock wave velocity and particle velocity are related to each other as (Marsh,1980):

$$
\mathrm{V}_{\mathrm{l}}=\mathrm{a}+\mathrm{b} \cdot \mathrm{V}_{\mathrm{p}}
$$

Where, $\mathrm{Vp}$ is the partial velocity, a and b are constants given in Stanley P. Marsh data book (Marsh, 1980) and shown in table (2).

Table 2. Material properties, (a) and (b) constant value of different metals (Marsh,1980; Callister, 2006)

\begin{tabular}{cccccc}
\hline Material & $\begin{array}{c}\text { Impedance } \\
\left(\mathrm{Kgm}^{-2} \mathrm{~s}^{-1} \times 10^{6}\right)\end{array}$ & $\begin{array}{c}\text { Density } \\
\left(\mathrm{Kg} / \mathrm{m}^{3}\right)\end{array}$ & $\begin{array}{c}\text { Constant (a) } \\
(\mathrm{Km} / \mathrm{s})\end{array}$ & $\begin{array}{c}\text { Constant } \\
(\mathrm{b})\end{array}$ & Absorbance \\
\hline $\mathrm{Al}$ & 49.5 & 2707 & 5.39 & 1.34 & 0.051 \\
$\mathrm{Cu}$ & 40.6 & 8954 & 3.94 & 1.49 & 0.042 \\
Indium (In) & 29.6 & 7310 & 2.49 & 1.50 & 0.099 \\
\hline
\end{tabular}

Table 3. Optical and thermal properties of used material ( Callister ,2006; Savchenko,2010).

\begin{tabular}{ccccccc}
\hline Material & $\begin{array}{c}\text { Melting } \\
\text { point }\left({ }^{\circ} \mathbf{C}\right)\end{array}$ & $\begin{array}{c}\text { Boiling } \\
\text { point }\left({ }^{\circ} \mathbf{C}\right)\end{array}$ & $\begin{array}{c}\text { Thermal expansion } \\
\text { coefficient } \\
\mathbf{1})\end{array}$ & $\begin{array}{c}\text { Thermal conductivity } \\
(\mathbf{W} / \mathbf{( m . K})\end{array}$ & $\begin{array}{c}\text { Thermal diffusivity } \\
\left(\mathbf{m}^{\mathbf{2}} / \mathbf{s}\right) \times \mathbf{1 0}^{-\mathbf{6}}\end{array}$ \\
\hline $\mathbf{A l}$ & 660.37 & 2467 & $21-24$ & 204.2 & 84.18 \\
$\mathbf{C u}$ & 1084.62 & 2562 & $16-16.7$ & 386 & 112.34 \\
$\begin{array}{c}\text { Indium } \\
(\text { In) }\end{array}$ & 156.59 & 2072 & $32.1-33$ & 33.07 & 19.4 \\
\hline
\end{tabular}

The spot area is measured by CCD camera system connected with optical system directly. Figure (5) shows the Al sample before and after depositing different metals, some removal (peeling) of the film is shown by increasing laser energy. The laser shock wave appears clearly with increasing laser energy; the spot on the film has an elliptical shape because the used laser gives higher order mode (TEM 0, 1). The deposited $\mathrm{Cu}$ film shows Shock wave more clearly than $\left(\mathrm{Al}_{\text {substrate }}\right.$ and $\left(\mathrm{Al} / \mathrm{In} / \mathrm{Al}_{\text {substrate }}\right)$ due to the thermal conductivity of $\mathrm{Cu}$ is higher than other metals, sandwich film $\left(\mathrm{Al} / \mathrm{Cu} / \mathrm{Al}_{\text {substrate}}\right)$ shows more wavy shape than $(\mathrm{In} / \mathrm{Cu} / \mathrm{Al}$ substrate) due to it has higher thermal diffusivity and conductivity as shown in table (3). 

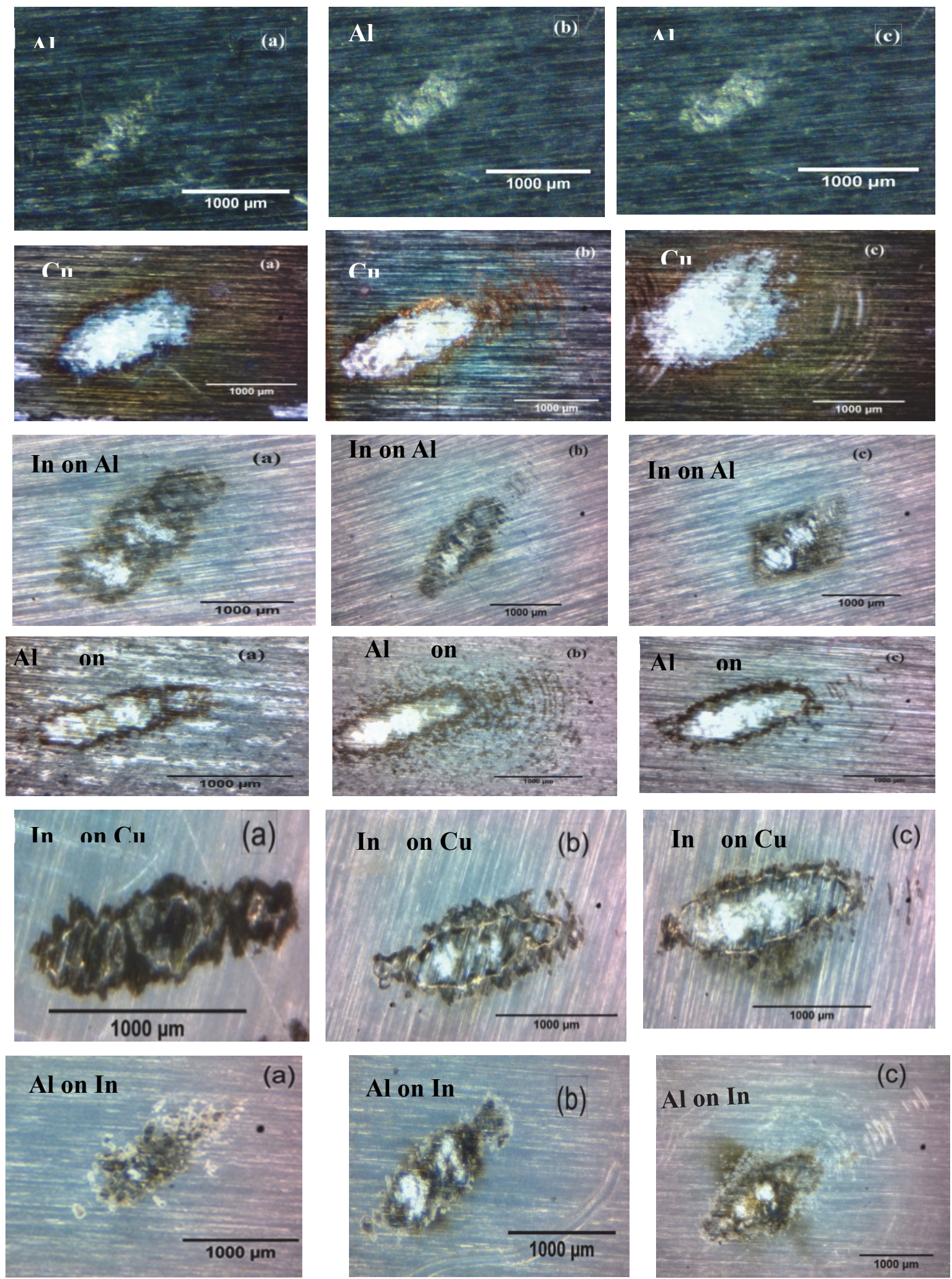

Figure 5. Different metals deposited on the Al substrate, (a) represent image at laser energy $5 \mathrm{~mJ}$, (b) at $40 \mathrm{~mJ}$, and (c) at $70 \mathrm{Mj}$

The shock pressure is founded from relation (6) the plotting between shock pressure and spot area is shown in figure (6), the spot area increased with increasing shock pressure due to the increasing laser intensity and surface 
temperature so increased the number of ions that emerged from the irradiated surface (Popoola et al., 2016), the relation between shock pressure and spot area nearly of the exponential than linear relation due to; (a) Avalanche breakdown within a material. A free electron becomes sufficiently accelerated by an externally applied force that it frees up additional electrons as it collides with atoms or molecules of the media. These secondary electrons also are accelerated, creating larger numbers of free electrons. The resulting exponential growth of electrons and ions may rapidly lead to complete breakdown of the material, (b) Alloying of substrate material with the thick film that undergoes fusion (Popoola et al., 2016).

When deposited metal films the area of laser spot is larger than Al without deposition, that due to the thickness of films is thin and the generated shock pressure is high due to confinement effects (Abdullahi\& Mamoun, 2014).to the cold side and the dissipation of laser energy are is faster than $\mathrm{In}, \mathrm{Cu}$ metal has a high melting and boiling point than In, also the generating high shock pressure from the $\mathrm{Cu}$ film because of it has higher shock impadence as shown previously in Table $(2,3)$

The multi-layer depositing $(\mathrm{Al} / \mathrm{Cu} / \mathrm{Al}$ substrate) shows a smaller spot area than single layer $(\mathrm{Cu} / \mathrm{Al}$ substrate) while ( $\mathrm{In} / \mathrm{Cu} / \mathrm{Al}$ substrate) shows a larger spot area than $(\mathrm{Cu} / \mathrm{Al}$ substrate) film due to the $\mathrm{Al}$ layer has a larger melting and boiling point than In metal.While ( $\mathrm{Al} / \mathrm{In} / \mathrm{Al}$ substrate) shows a comparable spot area with (In/ Al substrate) film and higher than (Al/In/ Al substrate) due to the first deposited layer (In) has a lower melting and boiling temperature and higher expansion coefficient than $(\mathrm{Cu})$ metal .

The shock pressure of deposited metal films $(\mathrm{Cu}, \mathrm{Al} / \mathrm{Cu} / \mathrm{Al}$ substrate $)$ is greater than $\mathrm{Al}$ before and after deposited other films on $\mathrm{Al}_{\text {substrate }}$ due to it has a high acoustic impedance.

When deposited $\mathrm{Cu} / \mathrm{Al}$ substrate the spot area is smaller than the film In/ $\mathrm{Al}$ due to , the $\mathrm{Cu}$ metal has high thermal conductivity and diffusivity so the rate of transfer of heat of a material from the hot side.

The particle velocity and shock velocity are calculated from relations (8) and (9) respectively, it illustrated in table (4) that shock velocity is great for ( $\mathrm{Al} / \mathrm{Cu} / \mathrm{Al}$ substrate) because it has a higher shock pressure than other films (the shock velocity and particle velocity are affected by the temperature; when the laser intensity has increased the temperature increased, so the shock wave tends to travel faster at higher temperatures (Abdullahi\& Mamoun,2014) ). Also the linear relation between shock velocity and particle velocity for all films was seen because of the dependence on each other.
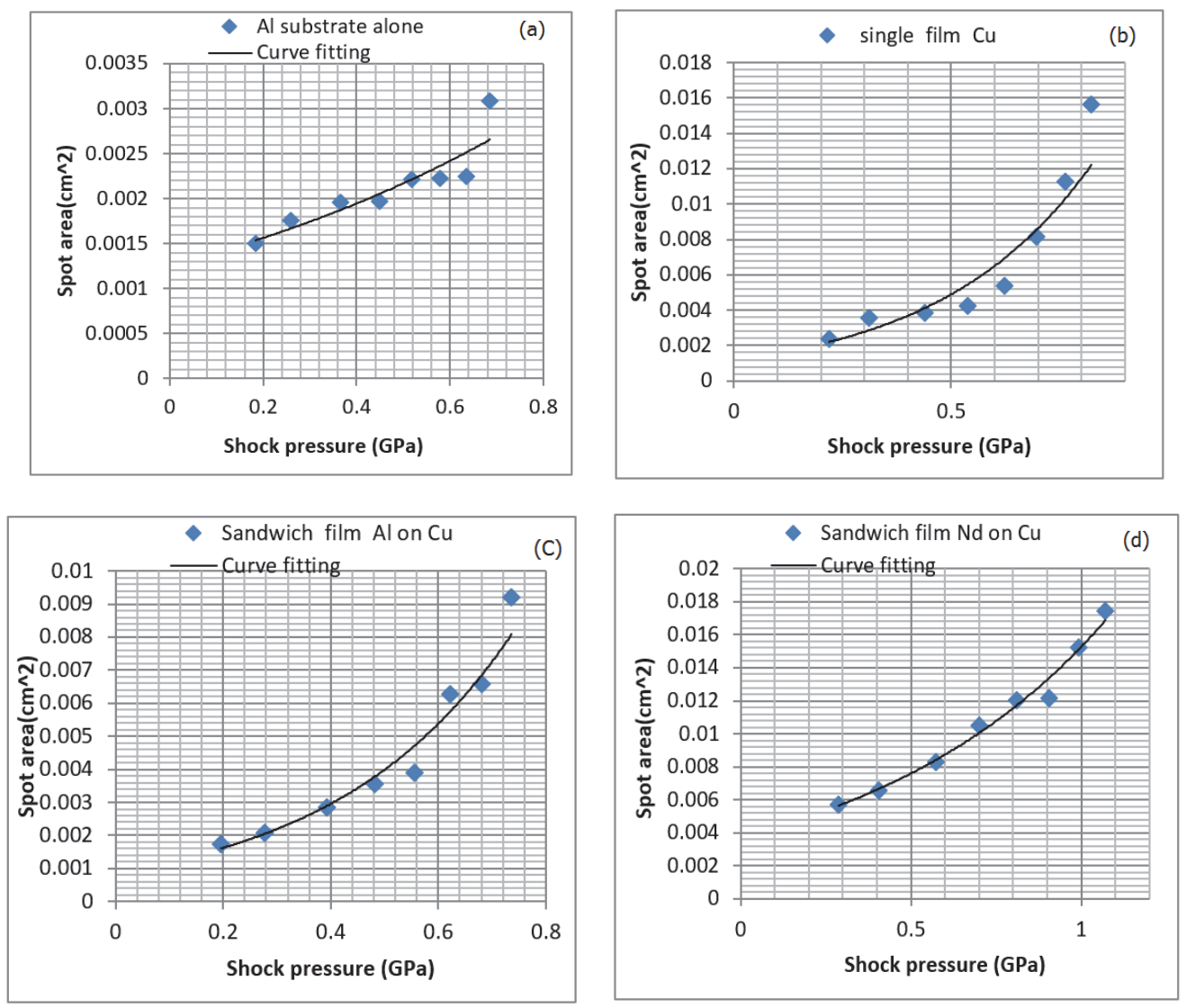

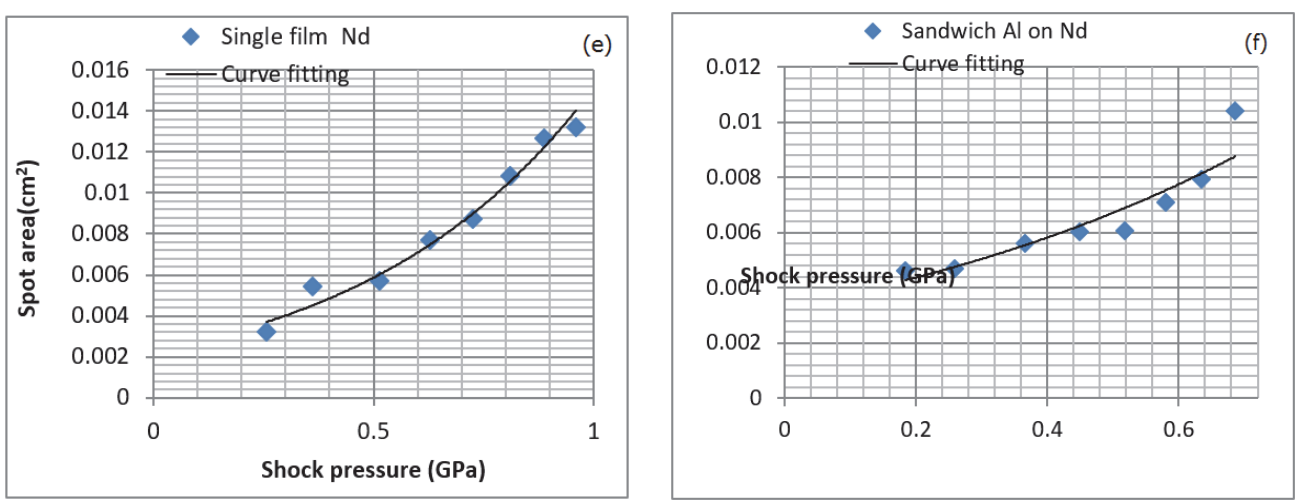

Figure 6. Relation between shock pressure and spot area of Al pure and after depositing different thin layer

Table 4. Shock wave and physical parameters by using LSP technique

\begin{tabular}{ccccccc}
\hline Thick film & $\mathrm{Al}_{\text {sub }}$ & $\mathrm{Cu} / \mathrm{Al}_{\text {sub }}$ & $\mathrm{Al} / \mathrm{Cu} / \mathrm{Al}_{\text {sub }}$ & $\mathrm{In} / \mathrm{Cu} / \mathrm{Al}_{\text {sub }}$ & $\mathrm{In} / \mathrm{Al}_{\text {sub }}$ & $\mathrm{Al} / \mathrm{In} / \mathrm{Al} 1_{\text {sub }}$ \\
\hline Spot area $\left(\mathrm{cm}^{2}\right)$ & 0.0016 & 0.003 & 0.0019 & 0.0061 & 0.0043 & 0.0047 \\
Shock pressure $(\mathrm{GPa})$ & 1.635 & 2.141 & 2.381 & 2.342 & 2.075 & 1.4246 \\
Particle velocity $(\mathrm{m} / \mathrm{s})$ & 94.35 & 85.77 & 116.399 & 61.22 & 115.326 & 80.1956 \\
Shock velocity $(\mathrm{m} / \mathrm{s})$ & 5512.24 & 5500.77 & 5541.74 & 4057.55 & 4161.43 & 4093.98 \\
Density $\left(\mathrm{g} / \mathrm{cm}^{3}\right)$ & 3143.95 & 4537.742 & 3691.49 & 5269.63 & 4322.81 & 4339.184 \\
\hline
\end{tabular}

\subsection{Mechanical Properties Using Laser Induced Shock Wave}

Tresca criterion or (Critical Shear Stress) considers that the cold-work process creates asymmetric pressure distribution around the hole. This assumption, used in the majority of the numerical models proposed, holds true for the split mandrel cold-working process, but is not sufficiently accurate for split sleeve cold-working (Pinho et al.2005). The internal pressure that leads to yielding onset is obtained as:

$$
\mathrm{P}=\frac{\sigma_{\mathrm{s}}}{2}
$$

The von Mises yield criterion or Critical Distortion Energy suggests that the yielding of materials begins when the second deviator stress invariant reaches a critical value. The internal pressure corresponding to yielding onset (Normal stress) is obtained as (Pinho et al., 2005):

$$
\mathrm{P}=\frac{\sigma}{\sqrt{3}}
$$

There are different types of acoustic waves, like (longitudinal or compression waves and transverse). Longitudinal acoustic wave relation with Young's modulus (E) is given as (Laugier\& H., 2011):

$$
\mathrm{V}_{\mathrm{l}}=\sqrt{\frac{\mathrm{E}}{\rho}}
$$

Where, $\mathrm{V}_{1}$ is the longitudinal density and $\rho$ is density. The relation between stress and strain is given by Hooke's law, which states (Pinho et al., 2005; Callister, 2006):

$$
\sigma=\epsilon \mathrm{E}
$$

Where, $\sigma$ is the applied stress, $\mathrm{E}$ is Young's modulus, and $\varepsilon$ is the resulting strain which measures the deformation of the material. The engineering strain is defined as (Laugier\& Ha ,2011; Callister ,2006):

$$
\epsilon=\frac{\mathrm{L}^{-} \mathrm{L}_{0}}{\mathrm{~L}_{0}}=\frac{\mathrm{V}_{\mathrm{p}}}{\mathrm{V}_{\mathrm{l}}}
$$

The measured mechanical properties are obtained using tensile test, figure (7) and table (5) shows the experimental result of the classical method. 

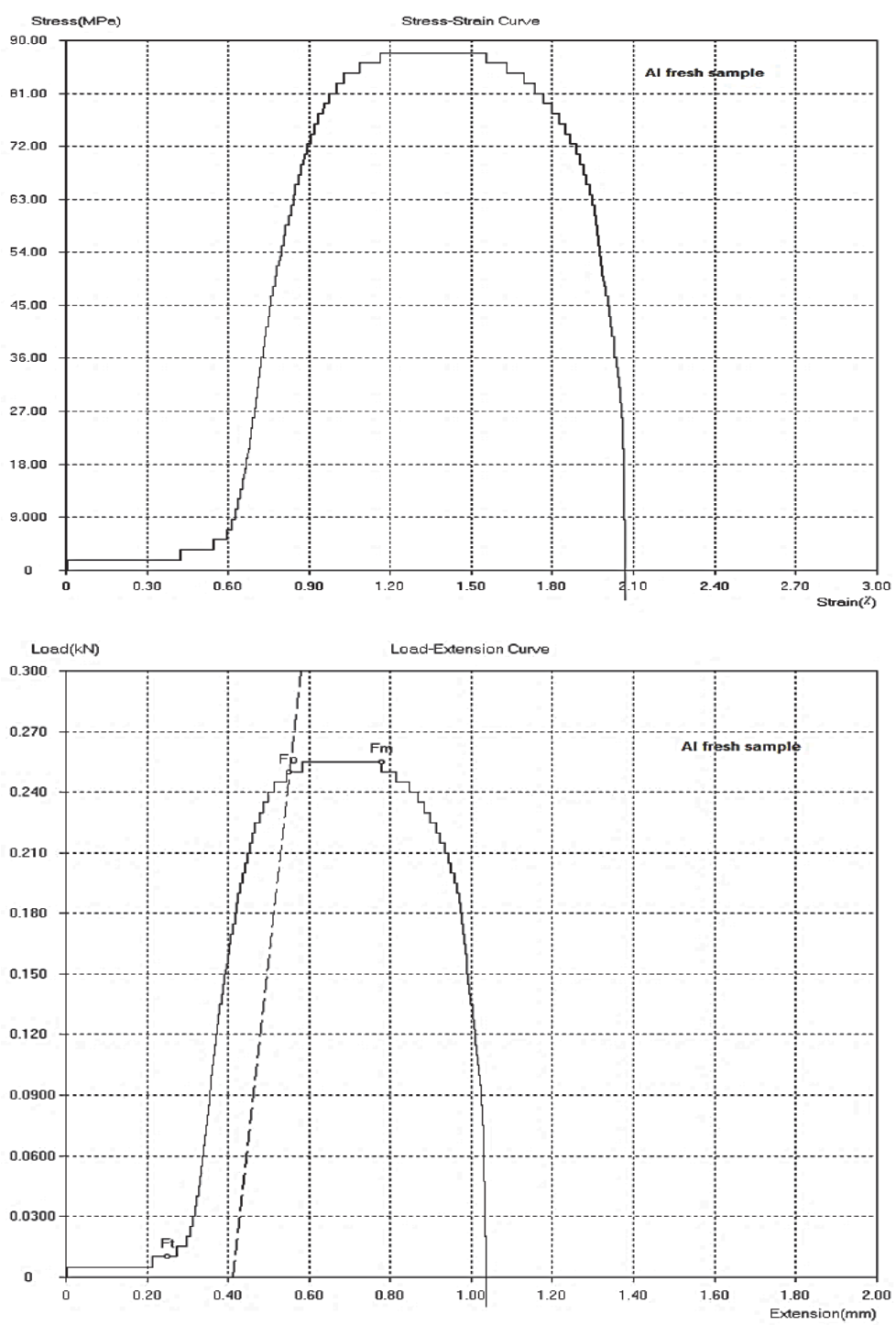

Figure 7. Classical Tensile test curves of Al metal, (a) Stress -strain curve, (b) Extension-loading curve

The obtained results by using (LSP) technique can be results by using previous equations and shown in table (4), the average value was taken of two less energy because higher energy makes melting and alloying as discussed previously. Shear stress and normal stress were calculated from Eq. 10 and 11 respectively, and shown in table (6), the stress (shear and normal) increased after depositing thick film and maximum value when deposited $(\mathrm{Cu}, \mathrm{Al} /$ $\mathrm{Cu} / \mathrm{Al}$ substrate) films due to large generated shock pressure from this film causing increase adhesion and bonding with the substrate as well as affecting on optical, mechanical and electrical properties. These stresses divided into extrinsic stresses arising from outer influences and intrinsic stresses generated in the film. The extrinsic stress being stress generated upon heating a film-substrate system with different thermal expansion coefficients although bending or wear substrate also gives rise to considerable stresses in the film. Intrinsic stresses generated in the film and related closely to the microstructure evolution, crystallographic defects and growth process of the film (Magnfält, 2013).

Table 5. Tensile test parameters of Al by classical methods.

\begin{tabular}{lllllll}
\hline $\begin{array}{l}\text { Max. } \\
\text { Force } \\
(\mathrm{KN})\end{array}$ & $\begin{array}{l}\text { Max. } \\
\text { Stress } \\
(\mathrm{MPa})\end{array}$ & $\begin{array}{l}\text { Yield } \\
\text { Force } \\
(\mathrm{KN})\end{array}$ & $\begin{array}{l}\text { Yield } \\
\text { Stress } \\
(\mathrm{MPa})\end{array}$ & $\begin{array}{l}\text { Fracture } \\
\text { Force }(\mathrm{KN})\end{array}$ & $\begin{array}{l}\text { Fracture } \\
\text { Stress (MPa) }\end{array}$ & $\begin{array}{l}\text { Young's } \\
\text { Modulus } \\
(\mathrm{GPa})\end{array}$ \\
\hline 0.2553 & 88 & 0.25 & 86 & 0.00075 & 2 & 28 \\
\hline
\end{tabular}


Young's modulus was determined from relation(12) and shown in table (6) was increased after deposited metal film $[(\mathrm{Cu}, \mathrm{Al} / \mathrm{Cu}) / \mathrm{Al}$ substrate $]$ that means it have higher stiffness and more adhesion with substrate and decreased for films [(In, In / Cu, and $\mathrm{Al}$ on In ) on Al substrate] that means it have low stiffness and poor adhesion with substrate, by comparing between classical measurement where Young's modulus was 28 Gpa found that the Young's modulus by LSP technique is nearest to the standard value of aluminum (70) Gpa (Callister, 2006; Crameri et al.2012).

A Strain that calculated from eq. (14) and its value illustrated in table (6) observed that higher value after deposited (In) metal film followed deposited $\mathrm{Al}$ and less value after deposited $\mathrm{Cu}$ metal film, because of the relation between strain and a dislocation (a crystallographic defect, or irregularity, within a crystal structure). The presence of dislocations strongly influences many of the properties of materials, also the lattice mismatch and modify the surface morphology that effected on strain (Callister, 2006).

Hardness or severity is the property of the material determines the material's ability to resist scratching. Hardiness depends on the chemical composition of the material as well as fine structure "Micro-structure". Hardness is dependent on elastic stiffness, plasticity, ductility, strength, strain, viscosity, and toughness (Callister, 2006). Hardness $(\mathrm{H})$ is calculated by knowing the maximum load $(\mathrm{P})$ and dividing it by the contact area of the indenter tip (A) (Crameri et al.2012; Oliver\& Pharr,2004):

$$
\mathrm{H}=\frac{\mathrm{P}}{\mathrm{A}}
$$

The films of $\left[(\mathrm{Cu}, \mathrm{Al} / \mathrm{Cu}) / \mathrm{AL}_{\text {substrate }}\right]$ have higher hardness rather than other films and the sandwich film $(\mathrm{Al} /$ $\mathrm{Cu} / \mathrm{AL}_{\text {substrate }}$ ) has higher hardness than $\mathrm{Cu}$ films and $\mathrm{Al}$ substrate where it has a smaller laser spot area than the single coating and $\mathrm{Al}$ alone due to the production of the second layer from thermal effects also it has a high Young's modulus rather than other films (the linear relation between Young's modulus and hardness (Chung et al., 2008)), and the formation of the intermetallic phases after the deposition process (Oliver\& Pharr,2004).

The hardness is low when deposited films (In) as a single and sandwich film because of it is brittle and easy to scratch rather than other film and substrate metal.

Table 6. Mechanical properties of Al before and after depositing a thick film, by taking the average value of first two little energy by using LSP technique

\begin{tabular}{|c|c|c|c|c|c|c|}
\hline Thick film & $\mathrm{Al}_{\text {sub }}$ & $\mathrm{Cu}$ on $\mathrm{Al}_{\text {sub }}$ & $\begin{array}{l}\mathrm{Al} \text { on } \mathrm{Cu} \text { on } \\
\mathrm{Al}_{\text {sub }}\end{array}$ & In on $\mathrm{Cu}$ on $\mathrm{Al}_{\text {sub }}$ & In on $\mathrm{Al}_{\text {sub }}$ & $\mathrm{Al}$ on In on $\mathrm{Al}_{\text {sub }}$ \\
\hline Shear stress $(\mathrm{GPa})$ & 3.2701 & 4.282 & 4.762 & 2.618 & 4.149 & 2.849 \\
\hline Normal stress (GPa) & 2.8320 & 3.708 & 4.12 & 2.267 & 3.593 & 2.4674 \\
\hline Strain & 0.0171 & 0.0156 & 0.021 & 0.01508 & 0.02771 & 0.0196 \\
\hline Young's modulus (GPa) & 95.53 & 137.304 & 113.368 & 86.756 & 74.8597 & 72.72458 \\
\hline Hardness $\left(\mathrm{Kg} / \mathrm{m}^{2}\right)$ & 1022.1 & 1195.19 & 1870.17 & 584.299 & 823.331 & 779.5959 \\
\hline
\end{tabular}

\section{Conclutions}

LSP shows an important alternative technique to the classical method by using different shapes to measure physical and mechanical properties of different materials, we can measure material density, shock pressure, particle velocity, shock velocity, normal stress, shear stress, strain, Young's modulus, and hardness. Young's modulus was measured by the classical method (Tensile test )and by (LSP), the measured value by LSP is nearest to standard value than classical method, so the purely mechanical effects are induced. Hardness was measured by (LSP) technique and gave interesting results. Best improvement of mechanical properties when deposited the sandwich films $(\mathrm{Al} / \mathrm{Cu} / \mathrm{Al}$ substrate) and single film $(\mathrm{Cu} / \mathrm{Al}$ substrate). LSP technique is considered as a cost-effective method to find mechanical and physical properties with accurate after comparing ensuing results of the classical and LSP method.

\section{Acknowledgments}

The author would like to a knowledge Al-Nahrain University and University of Technology for their help and assistance to complete this research.

\section{References}

Abdullahi, K. G., \& Mamoun, M. (2014). Laser Peening Process and Its Impact on Materials Properties in 
Comparison with Shot Peening and Ultrasonic Impact Peening. J. Materials, 7, 7925-7974. Retrieved from

Bartelt, T. L. M., ed. (2011). Industrial Automated Systems: instrumentation and Motion Control. Delmar Cengage learning. Copyrighted material, United states of America, P.210. Retrieved from https://www.slideshare.net/Pell1934yGjm5/download-industrial-automated-systems-instrumentation-andmotion-control-pdf-full-ebook-online-54988805

Callister, W. D. (2006). Materials Science and Engineering an Introduction. John Wiley \& Sons, Inc., p.133-155.

Chung, H., Weinberger, B. M., Yang, J., \& Tolbert, H. S. (2008). Correlation between hardness and elastic moduli of the ultra-incompressible transition metal diborides RuB2, OsB2, and ReB2. J. Appl. Phys. Lett., 92(1-3), pp.261904. Retrieved from http://aip.scitation.org/doi/abs/10.1063/1.2946665? journalCode=apl

Crameri, F., Schmeling, H., Golabek, G. J., Duretz, T., Orendt, R., Buiter,S. J. H., May, D. A., Kaus, B. J. P. (2012). A comparison of numerical surface topography calculations in geodynamic modeling: an evaluation of the 'sticky air' method. Geophysical Journal International, 189(1), 38-54.

Fabbro, R., \& Virmont, J. (1990). Physical study of laser produced plasma in confined geometry. J. Appl. Phys,

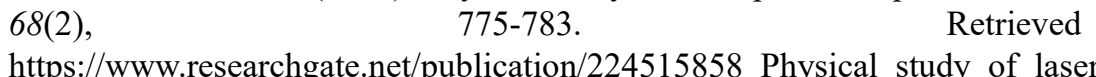

https://www.researchgate.net/publication/224

Heald, M. A., \& Marion, J. B. (2012). Classical Electromagnetic Radiation. Dover publications, 3ed, Inc. Mineola, New York, P.182. Retrieved from https://downloadflix.com/download/book/Classical\%20Electromagnetic\%20Radiation,\%20Third\%20Editio n\%20(Dover\%20Books\%20On\%20Physics).html?aff.id=9325\&aff.subid=7875

http://www.mdpi.com/1996-1944/7/12/7925

https://www.researchgate.net/publication/255729536_A_comparison_of_numerical_surface_topography_calcul ations_in_geodynamic_modelling_An_evaluation_of_the_sticky_air' method

Laugier, P., \& Ha, G. (2011). Bone quantitative ultrasound. Springer Science, 29-45. Retrieved from https://pdfs.semanticscholar.org/dd3f/fea179afecc0a6762da70508a53b22c6b887.pdf

Magnfält, D. (2013). Nucleation and stress generation in thin films deposited with a pulsed energetic deposition flux. Ph.D. Thesis, Printed by Liu-tryck Linköping, Sweden, p.13.

Marsh, S. P., ed. (1980). LASL Shock Hugoniot Data. University of California Press, pp. (4, 5, 57, 87). Retrieved from http://large.stanford.edu/publications/coal/references/docs/shd.pdf

Oliver, W. C., \& Pharr, G. M. (2004). Measurement of hardness and elastic modulus by instrumented indentation: Advances in understanding and refinements to methodology. J. Mater. Res., 19(1), 3-19. https://www.divaportal.org/smash/get/diva2:577768/FULLTEXT01.pdf

Pant, H. C., Shukla, M., \& Senecha, V. K. (2002). Equation-of-state studies using laser-driven shock wave propagation through layered foil targets. J. Current Science, 82(2), 149-157. Retrieved from https://pdfs.semanticscholar.org/9d0d/606a127ba170b73d50a8735d4c8d5d13fc1d.pdf

Peyre, P., \& Fabbro, R. (1995). Laser shock processing: a review of the physics and applications. J. Optical and Quantum Electronics, 27, 1213-1229. $\quad$ Retrieved from https://www.researchgate.net/publication/241544452_Physics_and_Applications_of_Lasershock_Processing

Pinho, S., Martins, B. H., \& Camanho, P. P. (2005). Residual stress field and reduction of stress intensity factors in cold-worked holes. J. Theoretical and Applied Fracture Mechanics, 44(2), 168-177. Retrieved from https://spiral.imperial.ac.uk/bitstream/10044/1/240/1/Residual\%20Stress\%20Field\%20and\%20Reduction\% 20 of $\% 20$ Stress $\% 20$ intensity $\% 20$ factors $\% 20$ in $\% 20$ coldworked $\% 20$ holes.pdf

Popoola, A. P. I., Fatoba, O. S., Nkosi1, H. W., \& Aigbodion, V. S. (2016). Surface Hardening of Aluminum by Laser alloying with Molybdenum and Zirconium powder. International Journal of Electrochemical Science, 11(1), 126-139. Retrieved from http://www.electrochemsci.org/papers/vol11/110100126.pdf

Rana, R. S., Rajesh, P., \& Das, S. (2012). Reviews on the Influences of Alloying elements on the Microstructure and Mechanical Properties of Aluminum Alloys and Aluminum Alloy Composites. International Journal of Scientific and Research Publications, 2(6), 1-7. Retrieved from http://www.ijsrp.org/research_paper_jun2012/ijsrp-June-2012-10.pdf 
Sankin ,G. N., Zhou, Y., \& Zhong, P., (2008). Focusing of shock waves induced by optical breakdown in water. $J$. Acoustical Society of America, 123(6), 4071-4081. Retrieved from http://www3.ntu.edu.sg/home/yfzhou/Publications/JAS004071.pdf

Savchenko, I.V., Stankus, S.V., \& Agazhanov, A. Sh., (2010). Heat transfer coefficients of liquid indium in the temperature range 470-1275 K.J.Thermophys. Aeromech. 17(1), $121-125$. Retrieved from https://link.springer.com/article/10.1134/S0869864310010142

\section{Copyrights}

Copyright for this article is retained by the author(s), with first publication rights granted to the journal.

This is an open-access article distributed under the terms and conditions of the Creative Commons Attribution license (http://creativecommons.org/licenses/by/4.0/). 